\title{
Análise das características dos pulmões disponibilizados para transplante no Estado de São Paulo*
}

\author{
Analysis of the characteristics of lungs \\ available for transplantation in São Paulo State
}

\author{
Jader Joel Machado Junqueira', Daniel Reis Waisberg', Gustavo \\ Sousa Noleto', Marcos Naoyuki Samano², Paulo Manuel \\ Pêgo-Fernandes $^{3}$ e Fabio Biscegli Jatene ${ }^{4}$
}

\begin{abstract}
Junqueira JJM, Waisberg DR, Noleto GS, Samano MN, Pego-Fernandes PM, Jatene FB. Análise das características dos pulmões disponibilizados para transplante no Estado de São Paulo. Rev Med (São Paulo). 2008 jan.-mar.;87(1):44-57.

RESUMO: Objetivos: Analisar a taxa de aproveitamento de pulmões disponibilizados em São Paulo em 2006, bem como caracterizar o perfil dos doadores de pulmão deste período. Métodos: Estudo retrospectivo de 497 prontuários de doadores de pulmão, no período de jan/2006 a dez/2006. Resultados: Dos 497 prontuários analisados, 149 (30\%) não tiveram os pulmões doados, sendo excluídos do estudo. Dos 348 doadores eleitos para o estudo, 56,9\% eram do sexo masculino, com idade média de $37,4 \pm 16,1$ anos. As principais causas da morte cerebral foram: AVC (40,5\%), TCE (34,2\%) e HSA (10,9\%). A grande maioria recebia drogas vasoativas $(90,5 \%)$, sendo que $13,5 \%$ haviam apresentado parada cárdio-respiratória. Do ponto de vista infeccioso, o leucograma médio foi de $15008 \pm 6467 \mathrm{~mm}^{3}, 67,8 \%$ recebiam antibioticoterapia e $26,1 \%$ apresentavam infecção pulmonar. Quase $40 \%$ dos doadores apresentavam alterações radiográficas. Apenas $4,9 \%$ dos doadores foram aceitos, representando 28 pulmões (taxa de aproveitamento de órgãos de 4,0\%). Os motivos de recusa foram: alteração gasométrica $(30,1 \%)$, infecção (23,7\%) e distância (10,9\%). Conclusão: A taxa de aproveitamento de pulmões em nosso meio é baixa. Além disso, mais de $50 \%$ das recusas deveram-se a gasometria arterial inadequada e infecção pulmonar. Aliar melhor cuidado ao potencial doador à menor rigidez nos critérios de seleção poderia aumentar a utilização dos órgãos doados.
\end{abstract}

DESCRITORES: Transplante de Pulmão. Doadores de Tecido. Seleção de Doador. Estudos retrospectivos.

\footnotetext{
* Prêmio Oswaldo Cruz - XXVI COMU, 2007 - Área Cirúrgica.

1. Acadêmico do curso de medicina da Faculdade de Medicina da Universidade de São Paulo (FMUSP).

2. Médico Pós-graduando de Cirurgia Torácica da FMUSP.

${ }^{3}$. Professor Associado da Disciplina de Cirurgia Torácica da FMUSP.

${ }^{4}$. Professor Titular da Disciplina de Cirurgia Torácica da FMUSP.

Endereço para correspondência: Laboratório Anátomo-Cirúrgico do Instituto do Coração (InCor) -HCFMUSP. R. Dr. Enéas de Carvalho Aguiar, 44 - 2ํA Andar / Bloco 1 - Cerqueira César. CEP: 05403-900. São Paulo, SP. e-mail: jader_junqueira@yahoo.com.br
} 


\section{INTRODUÇÃO}

D esde 1983, quando se relatou a execução do primeiro transplante de pulmão bem sucedido, pelo Toronto Lung Transplant Group, o aprimoramento de detalhes técnicos, a evolução das soluções de preservação de pulmão e a melhora no manejo pós-operatório dos pacientes têm sido uma constante.

Atualmente realizam-se aproximadamente 2000 procedimentos anuais, sendo que dados contabilizados pelo registro da International Society for Heart and Lung Transplantation (ISHLT) assinalam 22.684 transplantes realizados até $2005^{1}$, evidenciando ser este um tratamento efetivo para pacientes com pneumopatia grave ${ }^{2}$.

Apesar disto, o número de receptores em lista de espera tem aumentado de forma expressiva nos últimos 15 anos, excedendo o número de órgãos disponíveis ${ }^{3}$. Consequentemente, a mortalidade dos pacientes em lista de espera também tem aumentado, chegando a $50 \%$ em algumas casuísticas ${ }^{4}$.

Com o objetivo de tentar aumentar o número de doadores, várias estratégias têm sido propostas: xenotransplantes, transplantes intervivos ${ }^{5}$, doadores pós-parada cardíaca. Porém, devido a critérios médicos, técnicos e éticos, estas estratégias acabaram não tendo o impacto esperado sobre os índices de transplantes.

Neste contexto, passou-se a analisar os critérios de seleção dos órgãos aceitos para transplante. Estes critérios, criados no início da era de transplantes pulmonares e baseados em opiniões e experiências individuais, sem evidência de rigor científico ${ }^{6}$, objetivavam apenas a seleção de doadores ditos ideais. Entretanto, inúmeros grupos transplantadores têm mostrado que através da melhora no cuidado ao potencial doador e da expansão dos critérios de seleção (doadores não-ideais e marginais) é possível aumentar de maneira segura e expressiva a utilização dos órgãos doados ${ }^{7-9}$.

Mesmo com toda esta busca pelo melhor aproveitamento dos órgãos doados, seu real valor ainda se mantém muito aquém do ideal. Na literatura, são descritas taxas médias de aproveitamento próximas a $13,4 \%(6,1-27,1 \%)^{10}$, enquanto que em nosso meio essa porcentagem é ainda menor. O Brasil dispõe do maior programa público de transplantes do mundo, tendo realizado mais de 8500 transplantes em 2003 e tendo uma fila de espera de quase 60 mil pessoas no mesmo ano ${ }^{11}$.

Visando analisar os motivos da baixa taxa de aproveitamento de pulmões em nosso meio, buscamos caracterizar o perfil dos doadores de pulmão do Esta- do de São Paulo, correlacionando estes dados com o número de transplantes realizados e os motivos de recusa apresentados.

\section{CASUÍSTICA E MÉTODO}

\section{Seleção}

Realizamos um estudo retrospectivo de 497 prontuários de doadores de pulmão arquivados na Central de Transplantes da Secretaria de Saúde do Estado de São Paulo, no período de janeiro a dezembro de 2006. O trabalho foi avaliado e autorizado pela Comissão de Ética da Instituição. Como critério de exclusão, consideramos aqueles potenciais doadores que não tiveram os pulmões doados, mesmo que tenham sido doados outros órgãos. Assim, 149 (30,0\%) pacientes foram excluídos do estudo.

\section{Variáveis analisadas}

Nos $348(70,0 \%)$ doadores restantes foram avaliadas as seguintes variáveis:

a) Características gerais;

- Sexo, idade, cor (branco, negro, pardo e amarelo), peso, altura, perímetro torácico (medida na altura da linha mamilar) e tipagem sangüínea ( $A, B, O$ e $A B)$.

b) Comorbidades;

- Diabetes e tabagismo.

c) Intercorrências na UTI;

- Parada cárdio-respiratória, uso de drogas vasoativas, antibioticoterapia, infecção (presença e sítio) e intubação orotraqueal (dias).

d) Exames complementares;

- Relação $\mathrm{PO}_{2} / \mathrm{FiO}_{2}$, hemocultura, leucograma, sorologias (Chagas, Hepatite C, Hepatite B, HIV, HLTV I/II, Toxoplasmose, CMV e Sífilis), alteração na radiografia de tórax (focal ou difusa).

e) Causa da morte cerebral;

f) Situação do órgão doado.

- Recusado (motivo da recusa)

- Aceito (bilateral ou unilateral).

\section{Análise estatística}

Para a análise dos dados, foram calculados, em todas as variáveis estudadas, o número absoluto de casos, a média \pm desvio padrão e a variação (mínimo e máximo), bem como seu valor percentual em relação ao todo. 
Junqueira JJM et al. Análise das características dos pulmões disponibilizados para transplante.

\section{Aceitação do doador}

Por lei, todos os hospitais são obrigados a notificar a existência de um potencial doador. Inúmeros critérios devem ser atendidos para que haja a aceitação do órgão doado. 1) Declaração de morte cerebral, que é definida como a completa e irreversível perda das funções cerebrais e é determinada tanto por critérios puramente clínicos, obtidos por exames repetidos; quanto por exames complementares de avaliação da atividade cerebral ou fluxo sangüíneo cerebral (eletroencefalograma, angiografia cerebral ou USG Doppler transcraniano); 2) Indivíduos adultos podem registrar seu desejo de serem doadores de órgãos, entretanto, esta permissão também deve ser dada por um familiar no momento da confirmação da morte cerebral; 3) Testes sorológicos são realizados rotineiramente para vírus da hepatite $\mathrm{B}$, hepatite C, HIV, CMV, HTLV I/II, Chagas, Toxoplasmose e Sífilis (VDRL) e de acordo com seus resultados e os resultados de pesquisas sorológicas no receptor a utilização do órgão é decidida; 4) O transplante deve ser autorizado pelo Sistema Nacional de Transplantes e pelo Sistema Único de Saúde; 5) Os potenciais doadores de pulmão devem ainda se enquadrar nos critérios de doação padrão ou estendidos para transplante de pulmão ${ }^{12,13}$, como é mostrado na Tabela 1.

A fila para transplantes no SUS para cada órgão ou tecido é única, e o atendimento ocorre de acordo com o tempo em lista de espera, considerados critérios técnicos, de urgência e geográficos específicos para cada órgão ${ }^{11}$, de acordo com a Portaria $n^{\circ}$ 91/GM/MS de 23 de janeiro de 2001.

Tabela 1. Critérios de doador padrão e extendido para o transplante de pulmão

\begin{tabular}{lll}
\hline Critérios de Seleção & Doador Padrão & Doador Extendido \\
\hline Compatibilidade ABO & Idêntica & Compatível \\
Idade & $\leq 55$ anos & $>55$ anos \\
Tabagismo & $\leq 20$ maços-ano & $>20$ maços-ano \\
Trauma torácico & Ausência & Ausência de trauma extenso (trauma localizado) \\
Tempo de intubação & $\leq 7$ dias & $>7$ dias \\
Asma & Não & Sim \\
Câncer & Não (exceto pele e neoplasia in situ) & Tumor primário de SNC \\
Cultura de secreção & Negativa & Positiva (profilaxia adequada) \\
Relação PO2/FiO2* & $\geq 300$ & $<300$ \\
Radiografia de tórax & Normal & Alteração focal ou unilateral \\
Broncoscopia & Normal & Secreção em vias aéreas principais \\
Cirurgia cardiotorácica & Ausente & Eventualmente presente \\
Sorologias & Negativas & Citomegalovírus e Toxoplasmose toleradas
\end{tabular}

${ }^{*} \mathrm{FiO}_{2}$ ideal para o cálculo igual a $100 \%$ e PEEP igual a $5 \mathrm{cmH}_{2} \mathrm{O}$.

\section{RESULTADOS}

Analisamos um total de 348 doadores, 150 $(43,1 \%)$ do sexo feminino e $198(56,9 \%)$ do sexo masculino, com idade média de 37,47 \pm 16,16 anos (16 dias -82 anos). As variáveis analisadas, bem como os resultados obtidos são mostrados na Tabela 2 .

Para as variáveis idade, tabagismo, relação $\mathrm{PO}_{2} / \mathrm{FiO}_{2}$, alteração na radiografia de tórax e tempo de intubação orotraqueal (IOT), os valores foram analisados separadamente de acordo com os critérios padrões (CP) e extendidos (CE) para o transplante de pulmão. Assim, 300 doadores apresentavam idade menor de 55 anos (CP) e 339 doadores, idade menor de 65 anos (CE). Dentre os doadores em que foi possível o cálculo da relação $\mathrm{PO}_{2} / \mathrm{FiO}_{2}$ obtivemos um valor médio de $244 \pm 190$ (30 - 1366), sendo que 85 doadores apresentaram relação maior ou igual a 300 (CP), e 245 doadores, relação menor que 300 (CE).
Já entre os 138 doadores com radiografia de tórax alterada, $94(68,1 \%)$ puderam ser analisados quanto à localização da alteração pulmonar, sendo $35(25,3 \%)$ bilateral, $43(31,1 \%)$ direito e $16(11,6 \%)$ esquerdo. Foram consideradas alterações pulmonares aquelas descritas no prontuário do doador como infiltrado (39 casos), consolidação (34 casos), velamento (17 casos), opacidade (8 casos) e atelectasia (7 casos) Outras alterações como aumento da área cardíaca ( 8 casos) e pneumomediastino ( 2 casos) também foram considerados (Tabela 3). Para a variável tempo de IOT, dada em dias, obtivemos um valor médio de $5,18 \pm 4,26$ dias ( $12 \mathrm{~h}-33$ dias), sendo que 94 doadores apresentaram tempo de IOT menor que 48h (2 dias). Com relação à variável tabagismo, 278 (79,9\%) prontuários não apresentavam este dado descrito, impossibilitando a análise. Além disso, nos prontuários em que esta variável estava descrita, os valores não eram padronizados, sendo descritos como maços-ano, maços-dia, anos-maço ou cigarro- 
dia, dificultando a análise e trazendo dúvidas quanto à veracidade dos dados.

Tabela 2. Perfil dos doadores de pulmão disponibilizados no Estado de São Paulo no ano de 2006

\begin{tabular}{|c|c|c|}
\hline & Resultados & Avaliados \\
\hline \multicolumn{3}{|l|}{ Características Gerais } \\
\hline \multirow[t]{2}{*}{ Sexo } & Feminino: $150(43,1 \%)$ & \\
\hline & Masculino: 198 (56,9\%) & $348(100 \%)$ \\
\hline Idade* & $37,47 \pm 16,16$ anos ( 16 dias -82 anos) & $348(100 \%)$ \\
\hline \multirow[t]{4}{*}{ Cor } & Branco: $218(62,7 \%)$ & \\
\hline & Pardo: 78 (22,4\%) & \\
\hline & Negro: $38(10,9 \%)$ & \\
\hline & Amarelo: $7(2,0 \%)$ & $341(97,9 \%)$ \\
\hline \multirow[t]{4}{*}{ Tipagem Sangüínea } & O: $167(48,0 \%)$ & \\
\hline & A: $124(35,6 \%)$ & \\
\hline & B: $40(11,5 \%)$ & \\
\hline & $A B: 17(4,9 \%)$ & $348(100 \%)$ \\
\hline Peso & $70,67 \pm 17,60 \mathrm{~kg}(3,6-120 \mathrm{~kg})$ & $348(100 \%)$ \\
\hline Altura & $1,67 \pm 0,16 \mathrm{~m}(0,52-1,76 \mathrm{~m})$ & $346(99,4 \%)$ \\
\hline Perímetro Torácico & $91,70 \pm 18,20 \mathrm{~m}(21-178 \mathrm{~cm})$ & $292(83,9 \%)$ \\
\hline \multicolumn{3}{|l|}{ Comorbidades } \\
\hline \multirow[t]{2}{*}{ Diabetes } & Sim: $24(6,9 \%)$ & \\
\hline & Não: 315 (90,5\%) & $339(97,4 \%)$ \\
\hline \multirow[t]{2}{*}{ Tabagismo } & Sim: $64(18,4 \%)$ & \\
\hline & Não: $6(1,7 \%)$ & $70(20,1 \%)$ \\
\hline \multicolumn{3}{|l|}{ Intercorrências na UTI } \\
\hline \multirow[t]{2}{*}{ Parada Cardiorespiratória } & Sim: $47(13,5 \%)$ & \\
\hline & Não: $275(79,0 \%)$ & $322(92,5 \%)$ \\
\hline \multirow[t]{2}{*}{ Uso de Drogas Vasoativas } & Sim: $315(90,5 \%)$ & \\
\hline & Não: $33(9,5 \%)$ & $348(100 \%)$ \\
\hline \multirow[t]{2}{*}{ Antibioticoterapia } & Sim: $236(67,8 \%)$ & \\
\hline & Não: $71(20,4 \%)$ & $307(88,2 \%)$ \\
\hline \multirow[t]{2}{*}{ Presença de Infecção } & Sim: $100(28,8 \%)$ & \\
\hline & Não: $241(69,2 \%)$ & $341(97,9 \%)$ \\
\hline \multirow[t]{3}{*}{ Local da Infecção } & Pulmão: $91(26,1 \%)$ & \\
\hline & SNC: $3(0,9 \%)$ & \\
\hline & Trato Urinário: 3 (0,9\%) & $97(97 \%)$ \\
\hline Intubação Orotraqueal & $5,18 \pm 4,26$ dias $(12 \mathrm{~h}-33$ dias $)$ & $345(99,1 \%)$ \\
\hline \multicolumn{3}{|l|}{ Exames Complementares } \\
\hline Relação PO2/FiO2** & $244 \pm 190(30-1366)$ & $330(94,8 \%)$ \\
\hline Hemocultura & Positivo: 7 (2,0\%) & \\
\hline Negativo: $118(34,0 \%)$ & $125(35,9 \%)$ & \\
\hline Leucograma & $15008 \pm 6467(3380-37600) / \mathrm{mm} 3$ & $327(93,9 \%)$ \\
\hline Sorologias & Descrito na tabela 4 & \\
\hline \multirow[t]{2}{*}{ Radiografia de Tórax ${ }^{* \star *}$} & Normal: $180(51,7 \%)$ & \\
\hline & Alterada: $138(39,6 \%)$ & $318(91,3 \%)$ \\
\hline \multirow[t]{7}{*}{ Causa da Morte Cerebral ${ }^{\star \star \star \star}$} & AVC: $141(40,5 \%)$ & \\
\hline & TCE: $119(34,2 \%)$ & \\
\hline & HSA: $38(10,9 \%)$ & \\
\hline & FAF: $20(5,7 \%)$ & \\
\hline & Hipóxia / Anóxia Cerebral: 13 (3,7\%) & \\
\hline & Outros: $11(3,1 \%)$ & \\
\hline & Tumor de SNC: $6(1,7 \%)$ & $348(100 \%)$ \\
\hline \multirow[t]{2}{*}{ Situação do Doador } & Aceito: $17(4,9 \%)$ & \\
\hline & Recusado: 331 (95,1\%) & $348(100 \%)$ \\
\hline
\end{tabular}

* 300 doadores com idade < 55 anos e 339 doadores com idade < 65 anos; ** Dentre os doadores em que foi possível o cálculo da relação PO2/FiO2, 85 doadores apresentaram relação $\geq 300$ e 245 doadores, < 300; *** Dentre os doadores com radiografia de tórax alterada, 94 (68,1\%) puderam ser analisados quanto à localização da alteração pulmonar, sendo $35(25,3 \%)$ bilateral, 43 (31,1\%) direito e $16(11,6 \%)$ esquerdo; ${ }^{* * \star}$ AVC - Acidente Vascular Cerebral, TCE - Trauma Crânio Encefálico, HSA - Hemorragia Subaracnóidea, FAF - Ferimento por Arma de Fogo, SNC - Sistema Nervoso Central. 
Junqueira JJM et al. Análise das características dos pulmões disponibilizados para transplante.

Tabela 3. Alterações encontradas nas radiografias de tórax dos potenciais doadores de pulmão disponibilizados no Estado de São Paulo no ano de 2006

\begin{tabular}{|c|c|}
\hline Diagnóstico Radiológico (n) & Localização (n) \\
\hline \multicolumn{2}{|l|}{ Normal: $180(51,7 \%)$} \\
\hline \multicolumn{2}{|l|}{ Alterada: 138 (39,6\%) } \\
\hline \multirow[t]{3}{*}{ - Infiltrado: $39(11,2 \%)$} & Bilateral: $19(5,5 \%)$ \\
\hline & Direito: $19(5,5 \%)$ \\
\hline & Esquerdo: $1(0,2 \%)$ \\
\hline \multirow[t]{4}{*}{ - Consolidação: 34 (9,7\%) } & Bilateral: $5(1,4 \%)$ \\
\hline & Direito: $15(4,3 \%)$ \\
\hline & Esquerdo: $6(1,7 \%)$ \\
\hline & Não descrito: 8 (2,3\%) \\
\hline \multirow[t]{4}{*}{ - Velamento: 17 (4,9\%) } & Bilateral: $7(2,0 \%)$ \\
\hline & Direito: $2(0,6 \%)$ \\
\hline & Esquerdo: $4(1,2 \%)$ \\
\hline & Não descrito: $4(1,1 \%)$ \\
\hline \multicolumn{2}{|c|}{ - Aumento da Área Cardíaca: 8 (2,3\%) } \\
\hline \multirow[t]{3}{*}{ - Opacidade: 8 (2,3\%) } & Bilateral: $4(1,2 \%)$ \\
\hline & Direita: $1(0,3 \%)$ \\
\hline & Esquerda: $3(0,8 \%)$ \\
\hline \multirow[t]{2}{*}{ - Atelectasia: 7 (2,0\%) } & Direita: $5(1,4 \%)$ \\
\hline & Esquerda: $2(0,6 \%)$ \\
\hline \multicolumn{2}{|l|}{ - Pneumomediastino: $2(0,6 \%)$} \\
\hline \multicolumn{2}{|l|}{ - Outros: 23 (6,6\%) } \\
\hline Não descrita: 30 (8,6\%) & \\
\hline
\end{tabular}

Quanto às intercorrências na UTI, a variável parada cardiorespiratória esteve presente em 47 casos $(13,5 \%)$, sendo que o tempo de parada foi descrito em pouquíssimos casos, sendo desconsiderado para o efeito deste estudo. $O$ uso de drogas vasoativas esteve presente em 315 casos (90,5\%), sendo que as drogas utilizadas foram: noradrenalina (NOR), dopamina (DOP) e dobutamina (DOB), isoladamente ou em associações. Assim, em 223 casos $(64,1 \%)$ utilizou-se apenas NOR; 58 casos (16,6\%), apenas DOP; 1 caso (1,3\%), apenas DOB. As associações ocorreram nos demais casos, sendo que a associação NOR/DOP foi a mais freqüente, estando presente em 25 casos $(7,2 \%)$.

No grupo relacionado aos exames complementares, algumas considerações devem ser feitas. Com relação ao leucograma, partindo-se de uma normalização internacional que considera normal a contagem de leucócitos por milímetro cúbico $\left(\mathrm{mm}^{3}\right)$ entre 5 e 10 mil, obtivemos dentre os $327(93,9 \%)$ prontuários com estes dados, um total de $72(22,0 \%)$ com resultado dentro do normal esperado, $8(2,4 \%)$ com resultado inferior a 5000/mm $\mathrm{mm}^{3}$ e $247(75,5 \%)$ com resultado superior a $10000 / \mathrm{mm}^{3}$ (gráfico 1). $\mathrm{Na}$ análise das sorologias de hepatite $B$, apresentamos dois doadores com a tríade AgHBs positivo, Anti-HBs negativo e Anti-HBc positivo, indicando infecção aguda ou crônica. Dentre os doadores com AgHBs negativo, em 257 casos eram existentes a pesquisa dos outros dois marcadores (Anti-HBs e Anti-HBc). Assim, 23 casos tiveram como resultado Anti-HBs positivo e Anti-HBc positivo, indicando infecção prévia / imunidade; 35 casos apresentavam Anti-HBs positivo e Anti-HBc negativo, indicando resposta vacinal; 11 casos apresentavam Anti-HBs negativo e Anti-HBc positivo, indicando infecção remota e, por fim, 188 casos apresentavam Anti-HBs negativo e Anti-HBc negativo, indicando susceptibilidade. É importante ainda destacar quanto à pesquisa sorológica para CMV e Toxoplasmose, apresentamos apenas um caso de IgM positivo para CMV, sendo que os demais casos de positividade foram da classe IgG. Não houve positividade na pesquisa sorológica de HIV e HTLV I/II e apenas dois casos de positividade para Sífilis (VDRL). Na pesquisa de Chagas e vírus da hepatite $C$, apresentamos positividade em três casos distintos, respectivamente (Tabela 4). 
Gráfico 1. Contagem de leucócitos dos potenciais doadores de pulmão disponibilizados no Estado de São Paulo no ano de 2006.

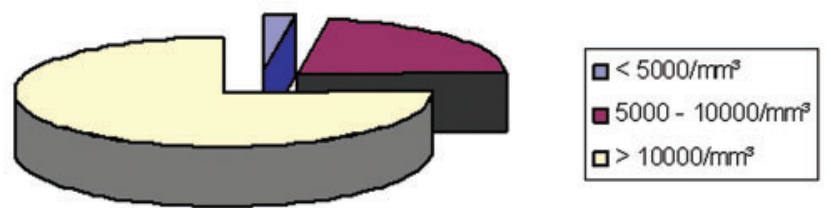

Tabela 4. Resultado da análise sorológica dos doadores de pulmão disponibilizados no Estado de São Paulo no ano de 2006.

\begin{tabular}{llll}
\hline Positivo & Negativo & \multicolumn{2}{c}{ Total Avaliado } \\
\hline Sorologia Chagas & $3(0,9 \%)$ & $341(98,0 \%)$ & $344(98,9 \%)$ \\
Sorologia HIV & 0 & $345(99,1 \%)$ & $245(99,1 \%)$ \\
Sorologia CMV* & $182(52,3 \%)$ & $29(8,3 \%)$ & $211(60,6 \%)$ \\
Sorologia HTLV I/II & 0 & $345(99,1 \%)$ & $345(99,1 \%)$ \\
Sorologia toxoplasmose** & $128(36,8 \%)$ & $82(23,6 \%)$ & $210(60,4 \%)$ \\
Sorologia sífilis (VDRL) & $2(0,6 \%)$ & $308(88,5 \%)$ & $310(89,1 \%)$ \\
Sorologia hepatite C & $3(0,9 \%)$ & $341(98,0 \%)$ & $344(98,9 \%)$ \\
Sorologia hepatite B & $343(98,5 \%)$ & $2(0,6 \%)$ & $345(99,1 \%)$ \\
AgHBs & $60(17,3 \%)$ & $204(58,6 \%)$ & $264(75,9 \%)$ \\
Anti-HBs & $38(10,9 \%)$ & $299(85,9 \%)$ & $337(96,8 \%)$ \\
Anti-HBc &
\end{tabular}

* Dentre os casos com resultado positivo, tivemos apenas um caso de IgM positivo, os demais foram IgG positivo; ** Dentre os casos com resultado positivo, todos foram IgG positivo, sem nenhum caso de IgM positivo; *** Obtivemos três casos com resultado indeterminado, não sendo considerado.

Dentre as causas de morte cerebral, tivemos o AVC, 141 casos (40,5\%), como a principal delas. A etiologia hemorrágica (AVCH) estava presente em 113 casos (32,5\%) e a isquêmica, em 28 casos ( $8,0 \%$ ). As lesões traumáticas, por ferimentos de arma de fogo (FAF) ocuparam a quarta posição, com 20 casos (5,7\%). Duas foram as localizações destes FAF's: crânio (19 casos) e região cervical (1 caso). Dentre as outras causas de morte temos a má formação arteriovenosa, o edema cerebral e a meningoencefalite bacteriana (Gráfico 2).

Gráfico 2. Causas de morte cerebral dos pontenciais doadores de pulmão disponibilizados no Estado de São Paulo no ano de 2006

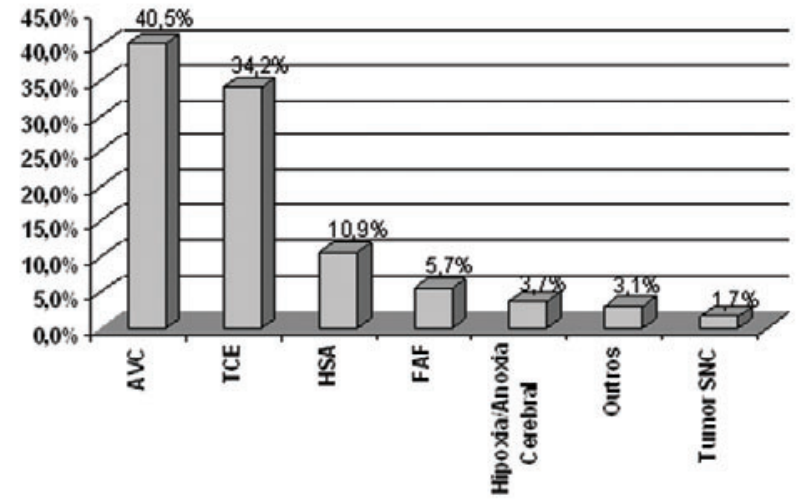


Junqueira JJM et al. Análise das características dos pulmões disponibilizados para transplante.

Algumas variáveis analisadas são facilmente notadas devido a sua baixa taxa de avaliação, como ocorre com o perímetro torácico, hemocultura e o tabagismo. Com relação ao perímetro torácico, atribuímos à ausência de sua medida em 56 casos $(16,1 \%)$ devido ao fato de que os prontuários provenientes de regiões fora do Estado de São Paulo não apresentam este item na avaliação do potencial doador, facilitando seu esquecimento durante a anamnese. Porém, isto não explicaria a totalidade dos prontuários sem esta medida, já que 14 deles são provenientes do Estado de São Paulo. Já a variável hemocultura apresentou uma ausência de dados em 223 casos (64\%). Esta importante falta de dados pode ser atribuída ao fato de que sua grande maioria apresentava-se "em andamento" durante o preenchimento do prontuário. Por fim, a variável tabagismo apresenta uma ausência de dados assustadora: 278 casos $(79,9 \%)$. O grande problema nesta variável provavelmente ocorreu pela falta de informação do familiar quanto à carga tabágica do paciente. Além disso, nos prontuários em que este item era preenchido, observamos uma falta de padronização dos dados, como já descrito acima.

As recusas dos pulmões ocorreram na grande maioria dos casos $(95,1 \%)$, sendo que os principais motivos encontram-se no Gráfico 3. No total foram 331 casos de recusa e 375 motivos de recusa. Desta forma, em 289 casos, 1 motivo de recusa foi descrito; em 41 casos, 2 motivos de recusa foram descritos; e em 1 paciente, 4 motivos de recusa foram descritos. Os três principais motivos são gasometria $(30,1 \%)$, infecção $(23,7 \%)$ e distância (10,9\%), sendo que juntos são responsáveis por mais de $60 \%$ das recusas.

Houve 17 casos de aceitação do pulmão doado, sendo que 11 foram bilaterais, 4 direitos e 2 esquerdos. Desta forma a taxa de utilização dos órgãos doados foi de 4,0\% (28 pulmões utilizados dentre 696 doados).

Gráfico 3. Motivo de recusa dos pulmões disponibilizados no Estado de São Paulo no ano de 2006

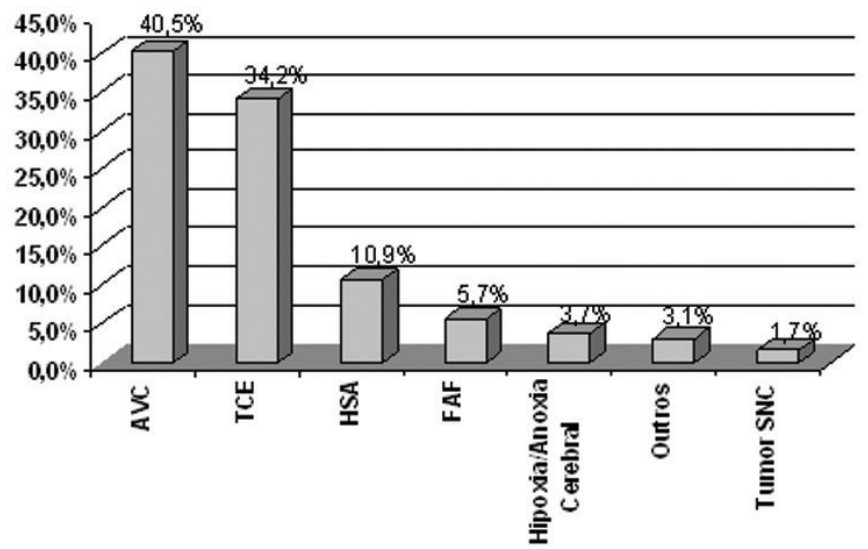

\section{DISCUSSÃO}

Há um grande debate na literatura mundial acerca dos critérios de aceitação de órgãos humanos destinados a transplantes, particularmente no caso do transplante pulmonar. Isto pode ser explicado pela crescente importância desse procedimento como alternativa terapêutica para pacientes com pneumopatias em estágio avançado ${ }^{2,14}$. Estas pneumopatias podem ser divididas em quatro classes principais: obstrutiva (enfisema, linfangioleiomiomatose), restritivas (fibrose pulmonar idiopática, colagenose, sarcoidose), supurativas (bronquiectasia, fibrose cística) e hipertensivas (Síndrome de Eisenmenger) ${ }^{15}$.

A rigidez dos critérios utilizados para seleção de doadores viáveis tem atuado como um dos fatores primordiais que contribuem para a restrição do número de órgãos disponibilizados para transplante ${ }^{16}$. De fato, a maior parte desses critérios foi estabelecida a partir de estudos retrospectivos, de casuísticas reduzidas, no início do desenvolvimento da técnica de transplante pulmonar6,17. Em vista da mortalidade na fila de espera elevada, que aumenta vertiginosamente a cada ano, e da quantidade crescente de pacientes necessitando de um transplante, há urgência em expandir o número de órgãos dis- 
poníveis para transplante ${ }^{3}$. Segundo Fischer et al. ${ }^{4}$, o tempo de espera dobrou nos últimos 10 anos nos EUA e em alguns centros europeus a mortalidade durante a espera elevou-se $50 \%$ neste mesmo período. Essa situação fortificou o interesse em reavaliar o conjunto de órgãos disponíveis atualmente, o que culminou com a criação de uma categoria denominada "doadores marginais", que inclui aqueles doadores cujas características não estão consoantes com os altamente seletivos critérios que estabelecem os "doadores ideais".

Em nosso meio, a porcentagem de utilização dos pulmões doados é extremamente reduzida (696 órgãos doados, 28 aproveitados, o que corresponde a um índice de 4,0\%, aproximadamente), quando comparada às taxas médias de aproveitamento mundial $13,4 \%(6,1-27,1 \%)^{10}$. Segundo dados provenientes da UNOS (United Network for Organ Sharing), no ano de 2004 apenas 15\% (970 de 12.000) dos pulmões doados mundialmente foram aproveitados ${ }^{18}$.

Já quando se compara estes dados com os obtidos para transplantes renal e hepático, esta baixa utilização fica ainda mais evidente. De acordo com os dados da Secretaria de Saúde do Estado de São Paulo, no ano de 2006 foram disponibilizados 368 fígados e 705 rins para transplantes, sendo que a taxa de aproveitamento foram de cerca de $91,3 \%$ e $90,2 \%$, respectivamente. É bem verdade que por causa das características individuais de cada órgão, sobretudo no que se refere ao tempo de isquemia e aos danos secundários as causas de morte, o aproveitamento dos pulmões doados jamais será tão elevado quanto os de rins ou fígados. Todavia a comparação acima é válida, pois reforça que a taxa de utilização de pulmões é, inegavelmente, baixa. Nesse sentido, um estudo sobre o perfil de doadores e, acima de tudo, uma análise dos motivos de recusa mostra-se bastante útil para determinar novas medidas que visem ao aumento do aproveitamento dos órgãos disponibilizados.

Vários centros de transplante no mundo têm realizado estudos sobre os efeitos de transplantes de pulmões provenientes de doadores marginais, a fim se avaliar até que ponto os critérios utilizados para doadores ideais deve ser seguido. Ware et al. ${ }^{19}$, através de um estudo retrospectivo com 29 pares de pulmões rejeitados para transplantes, mostraram que caso os critérios de edema pulmonar e de clearance de fluido alveolar fossem utilizados, aproximadamente $41 \%$ destes pulmões rejeitados poderiam ser aproveitados de maneira segura. Em alguns centros que promovem transplantes utilizando doadores marginais para casos emergenciais, já se constata uma elevação de $40 \%$ no número de procedimentos realizados ${ }^{7}$. A proporção de doadores aproveitáveis aumentou de $5 \%$ para $38 \%$ nos últimos 10 anos na Califórnia. O índice chegou a $43 \%$ em Toronto em 2002 e a $57 \%$, em Victoria, Austrália ${ }^{20}$.

Em nosso estudo houve 17 casos de aceitação do pulmão doado, sendo que 11 foram bilaterais, 4 direitos e 2 esquerdos. Em geral, o transplante bilateral é obrigatório nas doenças supurativas e na síndrome de Eisenmenger. Para as demais doenças, a indicação de transplante uni ou bilateral variará de acordo com as necessidades do paciente. A escassez de órgãos disponíveis para transplantes tem levado alguns centros a promoverem transplantes unilaterais mesmo em situações em que o procedimento bilateral seria mais adequado. É o que ocorre, por exemplo, com os pacientes portadores de DPOC (Doença Pulmonar Obstrutiva Crônica), dos quais somente 22\% são submetidos ao procedimento bilateral, em nível global $^{21}$. Nosso estudo demonstrou que a maioria dos transplantes realizados em 2006 foi bilaterais $(70,6 \%)$. Estudos têm mostrado que a escolha do tipo de transplante realizado (uni ou bilateral) não altera a sobrevida global dos pacientes. Burton et al. ${ }^{22}$, através de um estudo retrospectivo, analisaram 369 transplantes pulmonares (234 unilaterais, 113 bilaterais, 21 coração-pulmão e 1 lobular) realizados no período de janeiro de 1992 a dezembro de 2003 e concluíram, após seguimento de 1, 5 e 10 anos, que não houve diferença estatística significante na sobrevida dos pacientes submetidos a transplantes uni ou bilaterais $(p=0,40)$. Porém, quando se analisou os diferentes grupos de acordo com o diagnóstico patológico, observou-se que pacientes com fibrose pulmonar obtiveram maior morbidade peri-operatória (90 dias) quando comparados com pacientes com deficiência de $\alpha 1$-anti-tripsina $(\mathrm{p}=0,006)$ e pacientes com DPOC $(p=0,03)$.

Com relação aos motivos de recusa mais mencionados, constatamos a gasometria $(113-30.1 \%)$ como o principal deles, seguida de infecção (89$23,7 \%)$, distância $(41-10.9 \%)$ e idade $(33-8.8 \%)$.

\section{Gasometria}

Segundo os critérios de doador ideal, uma gasometria adequada corresponde a um valor de $\mathrm{PO}_{2} / \mathrm{FiO}_{2}$ maior que $300 \mathrm{mmHg}$, baseado em uma $\mathrm{FiO}_{2}$ de $100 \%$. Dos 17 doadores cujos órgãos foram utilizados, $6(35,2 \%)$ apresentavam razão $\mathrm{PO}_{2} / \mathrm{FiO}_{2}$ menor de 300 , sendo que 2 possuíam $\mathrm{FiO}_{2}$ menor que $100 \%$. Dessa forma, 11 doadores $(64.7 \%)$ podem ser classificados como ideais pelos critérios 
Junqueira JJM et al. Análise das características dos pulmões disponibilizados para transplante.

gasométricos. Os valores de classificação para um doador ideal por meio da gasometria foram sugeridos a partir de um relato de caso realizado por Harjula et al. ${ }^{17}$, em que ocorreu falência primária peri-operatória do enxerto após utilização de um doador com relação $\mathrm{PO}_{2} / \mathrm{FiO}_{2}$ menor que $250 \mathrm{mmHg}$ e $\mathrm{FiO}_{2}$ equivalente a $40 \%$. Essa ocorrência ilustra um dos argumentos centrais dos defensores da extensão dos critérios de seleção: a deficiência de embasamento científico no estabelecimento de tais regras de seleção. Ao longo dos últimos anos, foram realizados vários estudos que contestam tais critérios, demonstrando a viabilidade na utilização de doadores marginais. Shumway et al ${ }^{23}$, realizaram 25 transplantes utilizando doadores com fração $\mathrm{PO}_{2} / \mathrm{FiO}_{2}$ a partir de 250 e mostraram que a sobrevida em todos os casos, nos 18 meses de seguimento, não apresentou diferenças significativas em comparação aos índices de outros centros na época. Puskas et al. ${ }^{24}$, mostraram que a aferição da gasometria individualmente em cada pulmão pode indicar doadores passíveis de aproveitamento para transplantes unilaterais, quando o outro pulmão apresenta anormalidades na radiografia de tórax ou no exame de broncoscopia ou quando a gasometria total mostra-se insatisfatória. Além dos valores de gasometria, o momento de aferição de seus valores também é motivo de debate entre os centros de transplantes. Gabbay et al. ${ }^{25}$ mostraram que é a medida final pré-operatória a mais relevante para a seleção de doadores. McGiffin et al. ${ }^{26}$, mais recentemente, corroboraram que é a gasometria na sala de operação a mais importante e deve ser avaliada através de amostras das artérias e veias pulmonares esquerda e direita. Resultados semeIhantes foram obtidos por Straznicka et al. (2002) ${ }^{27}$ que, através de medidas agressivas, pôde elevar a gasometria de pulmões com razão $\mathrm{PO}_{2} / \mathrm{FiO}_{2}$ menor que $150 \mathrm{mmHg}$, sem impacto significante no curso pós-operatório e na sobrevida no primeiro ano. Estima-se que $30 \%$ dos pulmões doados podem ter sua gasometria elevada por meio dos métodos descritos acima ${ }^{28}$. A possibilidade de se melhorar a razão $\mathrm{PaO}_{2} / \mathrm{FiO}_{2}$ no doador através de uma intervenção ativa é real. Permite elevar seus valores a níveis superiores a 300 e, desta forma, disponibilizar mais pulmões para transplante sem comprometer de forma significativa a morbi-mortalidade dos receptores. A gasometria medida na UTI não deve ser um critério independente de exclusão dos doadores, uma vez que se tem observado uma discrepância entre esta e o valor medido no momento da retirada do órgão. Neste estudo observamos que muitos dos órgãos utilizados foram provenientes de doadores marginais pelo critério de gasometria. Conquanto a gasometria seja a maior causa de rejeição de órgãos, ela aparece, na maioria das vezes, associada a outro motivo de recusa, sendo considerada um motivo isolado em apenas em 39 casos (10,4\%).

\section{Infecção}

A infecção, além das alterações clínicas geradas, é usualmente comprovada por radiografia de tórax, hemocultura, e/ou leucograma alterados. Em casos de infecções purulentas, a broncoscopia também pode auxiliar no diagnóstico e tratamento (rolha de muco, corpo estranho, mau posicionamento do tubo traqueal) ${ }^{28}$. Por meio dos critérios tradicionais, a constatação de infecção impede a utilização do órgão ${ }^{29}$. Este é um dos principais motivos pelo qual doadores de múltiplos órgãos não se tornam fornecedores de pulmões, visto que determinadas infecções são toleradas para transplantes renais e hepáticos, por exemplo. Os principais fatores que favorecem o aparecimento de infecções são o aumento da probabilidade de aspiração pela morte cerebral e a presença de ventilação mecânica, que predispõe a colonização da árvore traqueobrônquica por eliminar os mecanismos de proteção das vias aéreas superiores ${ }^{30}$. Por causa disso, pelos critérios tradicionais, deve-se descartar órgãos proveniente de pacientes com tempo de IOT maior que 2 dias. Contudo, essa medida reduziria demasiadamente o número de pulmões disponibilizados para transplante e, deste modo, admite-se doadores marginais com até 14 dias de intubação. Em nosso estudo, constatamos que apenas $94(26.9 \%)$ dos potenciais doadores possuem tempo de IOT de até 2 dias. Por outro lado, apenas $11(3,18 \%)$ dos 345 doadores analisáveis apresentavam tempo de IOT superior a 14 dias. Entre aqueles cujos órgãos foram utilizados, apenas $5(29,4 \%)$ apresentavam tempo de IOT inferior a 48 horas, o que sugere que nosso meio está familiarizado com o uso dos doadores marginais por esse critério. Contudo, convém salientar que a média de tempo de IOT para os doadores efetivados foi de 3,6 dias, bem próximo ao limite superior do tempo ideal (48 horas), segundo os critérios tradicionais. De qualquer modo, a seleção de órgãos parece estar consoante com a tendência mundial de não descartar doadores apenas pelo tempo de IOT maior de 2 dias. Para tanto, esse fato deveria estar associado com algum outro motivo de recusa (mais comumente alterações na radiografia de tórax), conforme apontado por estudos de Bolton et al. ${ }^{31}$. Na nossa casuística, $8(2,1 \%)$ potenciais doadores tiveram, como motivo de recusa exclusivo, 
o elevado tempo de IOT. Nestes doadores a média de tempo de IOT foi de 16 dias (variando de 8 a 30 dias). Em outros três casos, o elevado tempo de IOT apresentou-se como um dos motivos de recusa.

Um dos métodos mais utilizados para verificar a existência de infecções pulmonares é a radiografia de tórax. Os requerimentos tradicionais exigem um exame sem alterações, embora seja comprovado que isso não exclui integralmente a ocorrência de anormalidades. Pierre et al. ${ }^{9}$ reportaram que infiltrados pulmonares unilaterais são aceitáveis para transplantes ao passo que infiltrados bilaterais não o são, ainda mais quando associados a atelectasias e secreções purulentas.

Diversos estudos dos efeitos de doadores com alterações na radiografia foram realizados, contudo, cabe lembrar que a classificação desses exames como normais ou não depende de critérios muito subjetivos ${ }^{32}$. Gabbay et al. ${ }^{25}$ demonstraram que, apesar de $39(60,9 \%)$ dos 64 doadores marginais analisados possuírem alterações radiológicas, não houve alterações na sobrevida dos receptores. Em um outro estudo retrospectivo conduzido por Meyers et al. ${ }^{33}$, reforçou-se que doadores marginais por tal critério influenciam de modo pouco expressivo a sobrevida. Em nossa casuística, nenhum órgão foi excluído do transplante apenas por apresentar alteração radiológica. Além disso, em dois casos de aceitação, havia alteração radiológica compatível com infiltrado unilateral. A despeito disso, o número de alterações observadas globalmente foi elevado $(138-39.6 \%)$, dos quais $35(10 \%)$ correspondiam a alterações bilaterais e $58(16,6 \%)$ unilaterais (nos demais casos não foi descrito o hemitórax alterado). Deu-se importância ao hemitórax alterado, quando a descrição da radiografia utilizava os termos: infiltrado, consolidação, velamento, opacidade ou atelectasia. Em 30 (8,6\%) doadores não havia quaisquer dados sobre a realização de radiografia de tórax em seus prontuários.

Outro método utilizado para a avaliação dos potenciais doadores quanto a quadros inflamatório/ infecciosos é a broncoscopia. Este teste é um prérequisito de diversas equipes de transplante pulmonar para aceitação de um órgão, especialmente quando há evidências de aspiração de conteúdo gástrico ou de infecção, uma vez que, como já foi dito, a presença de secreções purulentas usualmente contra-indica a utilização do órgão. Sua importância foi demonstrada por inúmeros estudos, dentre eles o conduzido por Riou et al ${ }^{34} \mathrm{em}$ que constataram que somente $33 \%$ dos doadores com morte cerebral e apenas $62 \%$ de todos os doadores considerados ideais apresentavam broncoscopia macroscopicamente sem alterações.

Apesar de macroscopicamente a presença de inflamação ou secreção purulenta ser facilmente identificável, alguns cuidados devem ser tomados com a interpretação dos resultados microscópicos. A coloração de Gram, quando positiva no aspirado traqueal, pode não significar uma pneumonia ativa, mas apenas uma coleção de secreção purulenta nas vias aéreas superiores. Ao contrário, a cultura quando positiva no lavado bronco-alveolar pode significar pneumonia ativa e estar associada com oxigenação reduzida no receptor, levando a um tempo maior de permanência na UTI, bem como a um prolongamento do tempo de ventilação ${ }^{35}$. Estudos de vários centros mostram uma incidência elevada, $80-97 \%$, de pacientes com presença de colonização traqueo-broncoalveolar ${ }^{36-38}$. Curiosamente, a presença de secreção bronquiolar estéril é mais rara. Os microorganismos mais encontrados são Staphylococcus, Cadida, $\mathrm{He}$ mophilus e Enterobacter ${ }^{17,38}$. Apesar da importância do exame de broncoscopia demonstrada nos diversos estudos apresentados, ele não é utilizado como procedimento de rotina para a seleção de doadores em nosso meio, em virtude principalmente de seu custo elevado, dificultando o acesso, e da dependência de um profissional especializado para sua realização.

Apesar de a hemocultura estar presente nos prontuários como uma informação a ser preenchida, a maioria deles não traz esse dado (223 doadores - 64\%). Observou-se resultado negativo em 118 (34\%) e resultado positivo apenas em 7 (2\%), dentre os quais somente 4 apresentavam o agente identificado. Dentre os doadores cujos pulmões foram aproveitados, $13(76,4 \%)$ não traziam informações sobre a hemocultura. A baixa ocorrência dos dados referentes à hemocultura nos prontuários não nos permite concluir que esse dado não está sendo utilizado pelas equipes para selecionar os doadores, uma vez que os doadores que não apresentam sinais de infecção não têm motivos para serem submetidos à coleta deste exame.

\section{Distância}

A terceira razão mais apontada para recusa de pulmões para transplante foi a distância entre o local de óbito do doador e a localização da equipe de transplante. Tal motivo é raramente encontrado na literatura internacional, primordialmente porque a maioria dos estudos advém de países europeus, EUA e Canadá. A pequena extensão territorial das nações do Velho Continente certamente contribui para a ausência desse problema. Contudo, isso não constitui 
Junqueira JJM et al. Análise das características dos pulmões disponibilizados para transplante.

o único e nem mesmo o principal fator pelo qual essa situação ocorre. Tais países exibem um sistema de transporte eficiente e, acima de tudo, possuem uma distribuição de equipes bastante homogênea pelo seu território. Isso também se observa na América do Norte, países de área territorial semelhante ao Brasil. Em nosso meio, a distância mostra-se uma causa demasiadamente pertinente, sobretudo porque as equipes estão muito concentradas em torno da capital do Estado de São Paulo. Ademais, uma rede de transporte de média eficiência atua como um fator coadjuvante. No presente estudo, verificou-se que 30 $(8,6 \%)$ doadores foram recusados exclusivamente por esse motivo, sendo que destes, 27 eram provenientes estados brasileiros diferentes de São Paulo e os 3 restantes advinham do interior deste estado. Os outros 11 doadores, para os quais a distância foi apontada como uma das razões de descarte, apresentavam outros motivos associados. Nesse sentido, a expansão de equipes de transplante para outros estados brasileiros se faz necessária.

A principal razão pela qual a distância atua como motivo para recusa de pulmões é por prolongar o tempo de isquemia fria (embora todo órgão seja submetido à perfusão com solução apropriada) que, caso seja muito elevado, torna o órgão sujeito a infecções. O tempo exato que um órgão pode resistir é ainda desconhecido. Os critérios tradicionais consideram o intervalo 4 a 6 horas como o máximo aceitável para transplantes de pulmão. Contudo a extensão desse critério certamente possibilitaria um aumento no número de pulmões disponíveis para transplante. Um dos maiores estudos publicados nesse contexto foi o realizado por Novick et al. ${ }^{39}$, que a partir da análise de 5052 receptores mostrou redução de um ano na sobrevida para transplantes utilizando órgãos com tempo de isquemia maior que 6 horas provenientes de doadores com idade maior que 55 anos. A presença de um desses fatores isolados (idade ou tempo de isquemia) não alterou a sobrevida. De forma semelhante, estudos de Fiser et al. ${ }^{40}$ mostraram que não há nenhuma correlação entre tempo de isquemia isolado e mortalidade dos receptores. Desse modo, apesar de não existir um limite máximo estabelecido para tempo de isquemia, conclui-se que os critérios clássicos tornaram-se muito rígidos e limitantes, talvez em função do progresso tecnológico na área de preservação de órgãos nas últimas décadas. Coerentemente, o grupo de Toronto reporta transplantes bem sucedidos utilizando órgãos com até 12 horas de tempo de isquemia, embora a própria equipe reconheça que períodos de tempo tão altos somente devam ser tolerados para receptores com expectativa de vida extremamente baixa ${ }^{20}$. Em nosso estudo, notou-se que o tempo de isquemia foi citado como motivo de recusa apenas duas vezes. Contudo, é provável que esse motivo tenha sido determinante em muitos dos casos em que a causa apontada foi, exclusivamente, a distância. Cabe lembrar que o maior tempo de isquemia permitido para órgãos como rim (até 48 horas) e fígado (12 a 24 horas) atua como um fator crucial para o grande aproveitamento dos doadores desses órgãos ${ }^{41}$. Além disso, e talvez mais relevantemente, a existência de um número maior de equipes de transplante para esses órgãos contribui para tais estatísticas mais favoráveis.

\section{Idade}

A quarta causa mais aferida em nosso estudo foi a idade do receptor. Pelos critérios ideais, a máxima idade permitida para transplante seria de 55 anos. Pulmões provenientes de doadores mais velhos expressam maiores possibilidades de neoplasias, infecções, além de processos enfisematosos, com redução da capacidade funcional pulmonar ${ }^{13}$. Novick et al. ${ }^{39}$ concluíram que a idade do doador menor de 10 anos ou maior de 50 anos pode estar associada com um aumento na mortalidade pós-transplante. Todavia, a idade do doador não se mostra como um preditor independente da sobrevivência a curto prazo. De modo contrário, houve uma interação negativa entre a idade do doador e tempo de isquemia aumentado, particularmente quando a idade era maior de 55 anos e o tempo de isquemia era maior de 6 horas. Em outro estudo mais recente, Christie et al. ${ }^{42}$ analisaram o impacto das características do doador em um estudo de coorte em 255 transplantes de pulmão consecutivos e observaram que a idade tinha um impacto independente sobre o desenvolvimento de disfunção primária do enxerto. Sabe-se que esta disfunção primária é responsável por significante morbidade precoce e mortalidade após transplante de pulmão $0^{43}$. Alguns grupos, no entanto, têm utilizado doadores de mais idade com sucesso, permitindo o aumento significativo de seu número de doadores e uma diminuição do tempo de espera em lista ${ }^{7,9,25}$. Doadores extremamente jovens, com idade menor que 10 anos, também eram recusados no início da era do transplante pulmonar. Contudo, esses doadores são muito mais utilizados atualmente, em razão dos transplantes para fibrose cística que ocorrem mais comumente em crianças ${ }^{44}$.

Em nossa casuística, dos 331 potenciais doadores recusados pela equipe médica, $33(8,8 \%)$ 
foram recusados por não preencherem o critério de idade. $\mathrm{Em} 20$ casos, a idade foi considerada motivo de recusa isolado, sendo que em 17 , a idade do doador era maior que 55 anos e em apenas um caso a idade era menor que 10 anos. Nos casos aceitos para transplante, nenhum apresentava idade maior que 55 anos e em dois casos a idade era menor ou igual a 10 anos. Provavelmente a ampliação do uso de doadores acima de 55 anos, deixando-se a recusa pela idade restrita aos casos em que houver um tempo de isquemia maior de seis horas, aumentaria o número de doadores aceitos em nosso serviço.

\section{CONCLUSÃO}

A taxa de aproveitamento de pulmões em nosso meio é baixa se comparada aos melhores modelos de captação mundiais. Grande parte das recusas deveu-se a gasometria arterial inadequada e infecção pulmonar, sendo estes fatores delatores da baixa qualidade do atendimento em terapia intensiva a que estes doadores estão submetidos. A ampla divulgação, na literatura médica, destes resultados se faz necessária e, neste sentido, compilamos os dados obtidos com a realização deste trabalho em um novo artigo já aceito para publicação este ano no Jornal Brasileiro de Pneumologia.

A demora no atendimento exerce impactos significativos sobre o bem-estar, as probabilidades de cura, a natureza e extensão das seqüelas nos pacientes, nos familiares e na sociedade ${ }^{11}$. Aliar melhor cuidado ao potencial doador à menor rigidez

nos critérios de seleção poderia aumentar a utilização dos órgãos doados com conseqüente diminuição na mortalidade e no tempo de espera dos pacientes.

Junqueira JJM, Waisberg DR, Noleto GS, Samano MN, Pego-Fernandes PM, Jatene FB. Analysis of the Characteristics of lungs available for transplantation in São Paulo State. Rev Med (São Paulo). 2008 jan.-mar.;87(1):44-57.

\begin{abstract}
S: Objectives: To analyze the utilization rate of lungs available for transplantation in São Paulo State during 2006, as well as to determine the lung donor profile in this same period. Methods: Retrospective study of 497 lung-donor's medical records during jan/2006 to dec/2006. Results: An amount of 149 (30\%) of the 497 general donors analyzed did not have their lungs offered to transplant and thus were precluded from the study. From the remaining 348 lung donors, $56.9 \%$ were man, with mean age of $37.4 \pm 16.1$ years. The main donor death causes were: stroke $(40.5 \%)$, cranial trauma $(34.2 \%)$ and subarachnoid haemorrhages $(10.9 \%)$. Most of these lung-donors received vasoactive agents (90.5\%) and $13.5 \%$ had cardiopulmonary arrest. Considering the infectious aspects, the mean leukocyte count was $15,008 \pm 6,467 /$ $\mathrm{mm}^{3}, 67.8 \%$ received anti-bacterial agents and $26.1 \%$ presented lung infection. Almost $40 \%$ of the lung-donors presented radiographic alterations. Only $4.9 \%$ of the lung-donors were accepted, representing 28 lungs (allograft utilization rate equivalent to $4.0 \%$ ). The main reasons for precluding donors were: gas-exchange alterations (30.1\%), infection (23.7\%) and distance (10.9\%). Conclusions: The lung utilization rate in São Paulo State can be considered low when compared to the best global models of tissue and organ procurement. Futhermore, more than $50 \%$ of the precluding reasons were improper gas-exchange and presence of infection. Combining better health care to the potential donor with the liberalization of lung-donor criteria could increase the allograft utilization rate.
\end{abstract}

KEY WORDS: Lung Transplantation. Tissue donors. Donor selection. Retrospective Studies.

\section{REFERÊNCIAS}

1. The International Society for Heart \& Lung Transplantation. Overall lung and adult lung transplantation statistics. [online] Available from: http:// www.ishlt.org.

2. Arcasoy SM, Kotloff RM. Lung transplantation. N Engl J Med. 1999;340(14):1081-91.

3. Hertz MI, Taylor DO, Trulock EP, Boucek MM,
Mohacsi PJ, Edwards LB, et al. The registry of the International Society for Heart and Lung Transplantation: nineteenth official report-2002. J Heart Lung Transplant. 2002;21(9):950-70.

4. Fisher AJ, Dark JH, Corris PA. Improving donor lung evaluation: a new approach to increase organ supply for lung transplantation. Thorax. 1998;53(10):818-20.

5. Cohen RG, Starnes VA. Living donor lung transplantation. World J Surg. 2001;25(2):244-50. 
Junqueira JJM et al. Análise das características dos pulmões disponibilizados para transplante.

6. Patterson GA, Cooper JD. Status of lung transplantation. Surg Clin North Am. 1988;68(3):545-58.

7. Bhorade SM, Vigneswaran W, McCabe MA, Garrity ER. Liberalization of donor criteria may expand the donor pool without adverse consequence in lung transplantation. J Heart Lung Transplant. 2000;19 (12):1199-204.

8. Aigner $\mathrm{C}$, Winkler $\mathrm{G}$, Jaksch $\mathrm{P}$, Seebacher $\mathrm{G}$, Lang G, Taghavi S, et al. Extended donor criteria for lung transplantation - a clinical reality. Eur J Cardiothorac Surg. 2005;27(5):757-61.

9. Pierre AF, Sekine Y, Hutcheon MA, Waddell TK, Keshavjee SH. Marginal donor lungs: a reassessment. J Thorac Cardiovasc Surg. 2002;123(3):421-7.

10. Association of Organ Procurement Organization. OPO voluntary survey on local organ donor and transplantation activity for 12 month totals, annual report. McLean (VA): The Association; 2000.

11. Marinho A. Um estudo sobre as filas para transplantes no Sistema Único de Saúde brasileiro. Cad Saúde Pública. 2006;22(10):2229-39.

12. Aigner C, Seebacher G, Klepetko W. Lung transplantation. Donor selection. Chest Surg Clin N Am. 2003;13(3):429-42.

13. Orens JB, Boehler A, de Perrot M, Estenne M, Glanville $A R$, Keshavjee $S$, et al. A review of lung transplant donor acceptability criteria. J Heart Lung Transplant. 2003;22(11):1183-200.

14. United Network for Organ Sharing. Guidelines for multiorgan donor management and procurement. UNOS Update. 1993;14-5.

15. Jatene FB, Samano MN. Transplante pulmonar. In: Moraes IN, Orgabizador. Tratado de clínica cirúrgica. São Paulo: Roca; 2005. v. 2, p. 2135-38.

16. Garrity ER. Pre-transplant evaluation of the donor/organ procurement. In: Norman DJ, Suki WN, editors. Primer on transplantation. Thorofare (N.J.): American Society of Transplant Physicians; 1998. p. 499-505.

17. Harjula A, Baldwin JC, Starnes VA, Stinson EB, Oyer PE, Jamieson SW, et al. Proper donor selection for heart-lung transplantation. The Stanford experience. J Thorac Cardiovasc Surg. 1987;94(6):874-80.

18. United Network for Organ Sharing. Critical data [online]. Available from: http://www.unos.org.

19. Ware LB, Wang Y, Fang X, Warnock M, Sakuma T, Hall TS, et al. Assessment of lungs rejected for transplantation and implications for donor selection. Lancet. 2002;360(9333):619-20.

20. de Perrot M, Snell GI, Babcock WD, Meyers BF, Patterson G, Hodges TN, et al. Strategies to optimize the use of currently available lung donors. J Heart Lung Transplant. 2004;23(10):1127-34.

21. Hosenpud JD, Bennet LE, Keck BM, Boucek MM, Novick RJ. The registry of the International Society for Heart and Lung Transplantation: eighteenth official report-2001. J Heart Lung Transplant. 2001;20(8):805-15.

22. Burton CM, Milman N, Carlsen J, Arendrup H, Eliasen $\mathrm{K}$, Andersen CB, et al. The Copenhagen National Lung
Transplant: survival after single lung, double lung and heart-lung transplantation. J Heart Lung Transplant. 2005;24(11):1834-43.

23. Shumway SJ, Hertz MI, Petty MG, Bolman RM $3^{\text {rd }}$. Liberalization of donor criteria in lung and heart-lung transplantation. Ann Thorac Surg. 1994;57(1):92-5.

24. Puskas JD, Winton TL, Miller JD, Scavuzzo M, Patterson GA. Unilateral donor lung dysfunction does not preclude successful contralateral single lung transplantation. J Thorac Cardiovasc Surg. 1992;103(5):1015-7.

25. Gabbay E, Williams TJ, Griffiths AP, Macfarlane LM, Kotsimbos TC, Esmore DS, et al. Maximizing the utilization of donor organs offered for lung transplantation. Am J Respir Crit Care Med. 1999;160(1):265-71.

26. McGiffin DC, Zorn GL Jr, Young KR Jr., Kirklin JK, Leon $\mathrm{KJ}$, Wille $\mathrm{KM}$, et al. The intensive care unit oxygen challenge should not be used for donor lung function decision-making. J Heart Lung Transplant. 2005;24(11):1902-5.

27. Straznicka M, Follette DM, Eisner MD, Roberts PF, Menza RL, Babcock WD. Aggressive management of lung donors classified as unacceptable: excellent recipient survival one year after transplantation. J Thorac Cardiovasc Surg. 2002;124(2):250-8.

28. de Perrot M, Snell GI, Babcock WD, Meyers BF, Patterson G, Hodges TN, et al. Strategies to optimize the use of currently available lung donors. J Heart Lung Transplant. 2004;23(10):1127-34.

29. Winton TL, Miller JD, Scavuzzo M, Maurer JR, Patterson GA. Donor selection for pulmonary transplantation. The Toronto Lung Transplant Group. Transplant Proc. 1991;23(5):2472-4.

30. Egan T, Boychuk JE, Rosato K, Cooper JD. Whence the lungs? A study to assess suitability of donor lungs for transplantation. Transplantation. 1992;53(2):420-2.

31. Bolton JS, Padia SA, Borja MC, Becker P, Orens JB, Wiener $\mathrm{C}$, et al. The predictive value and inter-observer variability of donor chest radiograph interpretation in lung transplantation. Eur J Cardiothorac Surg. 2003;23(4):484-7.

32. Thabut G, Mal H, Cerrina J, Dartevelle D, Dromer C, Velly JF, et al. Influence of donor characteristics on outcome after lung transplantation: a multicenter study. J Heart Lung Transplant. 2005;24(9):1347-53.

33. Meyers BF, Lynch J, Trulock EP, Guthrie TJ, Cooper JD, Patterson GA. Lung transplantation: a decade of experience. Ann Surg. 1999;230(3):362-70.

34. Riou B, Guesde R, Jacquens $Y$, Duranteau R, Viars P. Fiberoptic bronchoscopy in brain-dead organ donors. Am J Respir Crit Care Med. 1994;150(2):558-60.

35. Avlonitis VS, Krause A, Luzzi L, Powell H, Phillips $\mathrm{JA}$, Corris PA, et al. Bacterial colonization of the donor lower airways is a predictor of poor outcome in lung transplantation. Eur J Cardiothorac Surg. 2003;24(4):601-7.

36. Griffith BP, Zenati M. The pulmonary donor. Clin Chest Med. 1990;11(2):217-26. 
37. Stewart S, Ciulli F, Wells FC, Wallwork J. Pathology of unused donor lungs. Transplant Proc. 1993;25(1 Pt 2):1167-8.

38. Low DE, Kaiser LR, Haydock DA, Trulok E, Cooper JD. The donor lung: infectious and pathologic factors affecting outcome in lung transplantation. J Thorac Cardiovasc Surg. 1993;106(4):614-21.

39. Novick RJ, Bennett LE, Meyer DM, Hosenpud JD. Influence of graft ischemic time and donor age on survival after lung transplantation. J Heart Lung Transplant. 1999;18(5):425-31.

40. Fiser SM, Kron IL, Long SM, Kaza AK, Kern JA, Cassada DC, et al. Influence of graft ischemic time on outcome following lung transplantation. J Heart Lung Transplant. 2001;20(12):1291-6.
41. Joint Commission on Accreditation of Healthcare Organizations. Health care at crossroads: strategies for narrowing the organ donation gap and protecting patients. Washington (DC); 2004.

42. Christie JD, Kotloff RM, Pochettino A, Arcasoy SM, Rosengard BR, Landis JR. Clinical risk factors for primary graft failure following lung transplantation. Chest. 2003;124(4):1232-41.

43. Trulock EP, Edwards LB, Taylor DO, Boucek MM, Mohacsi PJ, Keck BM, et al. The registry of the International Society for Heart and Lung Transplantation: twentieth official adult lung and heart-lung transplant report-2003. J Heart Lung Transplant. 2003;22(6):625-35.

44. Knight SR, Dresler C. Results of lung transplantation. Semin Thorac Cardiovasc Surg. 1992;4(2):107-12. 